\title{
Electrospray ionization/ mass spectrometric observation of ligand exchange of zinc pyrithione with amino acids
}

\author{
Hiroshi Moriwaki* ${ }^{1}$, Masanori Okabayashi ${ }^{2}$, Takehiro Watanabe ${ }^{2}$, Hideya Kawasaki ${ }^{2}$ \\ and Ryuichi Arakawa*2 \\ ${ }^{1}$ Shinshu University, Faculty of Textile Science and Technology, Division of applied biology, 3-15-1, \\ Tokida, Ueda 386-8567, Japan, E-mail: moriwaki@shinshu-u.ac.jp \\ ${ }^{2}$ Kansai University, Department of Applied Chemistry, Yamate-cho 3-3-35, Suita, Osaka 564-8680, \\ Japan.
}

* To whom correspondence should be addressed.

E-mail: moriwaki@shinshu-u.ac.jp

E-mail: arak@ipcku.kansai-u.ac.jp

\begin{abstract}
Zinc pyrithione (ZnPT) is widely used as an antidandruff or antifouling reagent. However, this compound is considered toxic, such as the teratogenic effect, to aquatic lives, and it is important to clarify the mechanism of its toxicity. In this study, the interactions between ZnPT and amino acids were observed using ESI/MS in order to obtain information on the activity of ZnPT within the living body. The ZnPT complex ([ZnPT-ligand+Amino acid] ${ }^{+}$), in which the ligand of ZnPT was exchanged by the amino acid, was detected in ZnPT solutions mixed with one of 20 amino acids by ESI/MS. Histidine and cysteine, in particular, showed a high reactivity with ZnPT, while serine and glycine showed a low reactivity. The complexes of ZnPT and a peptide were also observed by the ESI/MS measurement of the aqueous solution containing ZnPT with the peptide. These results would be useful for thinking the mechanism of ZnPT toxicities to living creatures.
\end{abstract}

Key words: zinc pyrithione, antifouling compound, teratogenic effect, electrospray ionization, ligand exchange

\section{Introduction}

Zinc pyrithione (ZnPT) is the zinc chelate of 2-pyridinethiol-1-oxide (Fig. 1). This compound is widely used as a bactericide, fungicide and algicide in various products, such as anti-dandruff shampoos. The compound, in particular, has been effectively used as a ship-antifouling agent being 
an alternative to organotin compounds. Therefore, the toxicological and ecotoxicological effects of $\mathrm{ZnPT}$ on aquatic life are important. A few studies have examined the toxicity of ZnPT on aquatic organisms, and it has been clarified that ZnPT can be potentially highly toxic. ${ }^{1-4}$ Goka reported that embryos of the zebra fish and Japanese Medaka exposed to sublethal concentrations of ZnPT (0.003-0.007 mg/L) developed spinal cord malformations. ${ }^{1}$ In addition, Okumura et al. reported that ZnPT ( $>0.01 \mathrm{fg} / \mathrm{L}$ ) inhibited sea urchin embryo development. ${ }^{2}$ It is well known that ZnPT is non-persistent in the environment due to the fact that the compound photolyses and rapidly degrades. However, in low light situations and at night, the compound could be retained in the environment. ${ }^{5,6}$ Furthermore, ZnPT influences aquatic wild life at markedly low concentrations. ${ }^{1,2,6}$ Therefore, it is important to understand the influence of the compound on wild life and the mechanisms of the toxicity of $\mathrm{ZnPT}$ in order to determine the appropriate use of $\mathrm{ZnPT}$. At this stage, the mechanism of the toxicity of ZnPT remains uncertain.

Interactions between proteins and environment pollutants often cause various toxicities, such as defective development ${ }^{7}$, and there is a possibility that the interactions between ZnPT with proteins influence the health of wild life. However, there is no report about the interactions between ZnPT and biological materials. It was reported that $\mathrm{ZnPT}$ did not reveal the gene toxicity. ${ }^{8}$ This fact indicates that the toxicities of ZnPT would be not caused by the interaction between DNA and ZnPT, and it is thought that the interaction between protein and ZnPT plays an important role of the toxicity of ZnPT.

Electrospray-ionization mass spectrometry (ESI/MS) is a very powerful method for the characterization and identification of interactions between polar species, because the technique is a very soft ionization method., ${ }^{9,10}$ The technique has been frequently used for the analysis of the interactions between biological materials and chemicals ${ }^{11,12}$ or metal ions. ${ }^{13}$ However, it is very difficult to research the interaction between proteins and substances by ESI/MS, because there are many complex binding sites and forms between protein and substances.

There were several examples that an investigation of a solution of a target substance with amino acids by ESI/MS was studied in order to initially serve as a simple model for complex interactions of the substance in proteins. ${ }^{14,15,16}$ In this research, solutions containing ZnPT and amino acids were measured by ESI/MS for the purpose of gaining information on the behavior of ZnPT with amino acids and peptides. This approach would be useful for understanding the interaction between ZnPT and proteins and the toxicological mechanisms of ZnPT.

\section{Experimental \\ Materials}

All solvents were of HPLC grade and all the other chemicals were of analytical-reagent grade. Glycine (Gly), L-aspartic acid (Asp), L-glutamic acid (Glu), L-phenylalanine (Phe), L-alanine (Ala), L-histidine monohydrochloride monohydrate (His), L-isoleucine (Ile), L-lysine monohydrochloride (Lys), L-leucine (Leu), L-methionine (Met), L-proline (Pro), L-arginine hydrochloride (Arg), L-serine (Ser), L-threonine (Thr), L-valine (Val), L-tryptophan (Trp) and L-tyrosine (Tyr) were purchased from the Ajinomoto-Takara Corporation (Tokyo, Japan). L-cysteine (Cys) was obtained from MP Biomedicals, LLC (Irvine, CA, USA). $\mathrm{N}_{\alpha^{-}}$(tert-butoxycarbonyl)-L-histidine and a peptide, Leucine-Enkephalin (Tyr-Gly-Gly-Phe-Leu; Molecular weight: 555.626, theoretical mass: 555.276) was purchased from PEPTIDE INSTITUTE INC. (Osaka, Japan). ZnPT (Molecular weight: 317.70, theoretical mass of the most abundant isomer: 315.932), ammonium acetate, L-glutamine, L-asparagine and methanol were purchased from Wako Pure Chemical Industries, Ltd. (Osaka, Japan). Ultrapure water was produced by an automatic water distillation apparatus (RFD250NB, ADVANTEC, Tokyo, Japan). Polypropylene tubes were used for the preparation and storage of the ZnPT solution in order to avoid any adsorption. A stock solution with a concentration of $0.5 \mathrm{mM}$ was prepared by the dissolution of $\mathrm{ZnPT}$ in methanol. The solution was stored at $4{ }^{\circ} \mathrm{C}$ in the dark.

ESI/MS analysis

The ESI/MS was performed using a LC tandem mass spectrometer TSQ7000 system (Finnigan MAT). The ESI/MS operating conditions are as follows. Ionization: ESI-positive ionization: ESI voltage: $4.5 \mathrm{kV}$; capillary temperature: $210{ }^{\circ} \mathrm{C}$; Drift voltage: $50 \mathrm{~V}$ and sheath gas pressure: $50 \mathrm{psi}$ of nitrogen. The peak intensities were obtained from the average of 30 scans. 
The methanol/ water (1/1; v/v) solutions containing ZnPT (0, 10, 20, 30, 40, 50 or $100 \mu \mathrm{M})$ and one of the 20 kinds of amino acids ( 30 or $100 \mu \mathrm{M})$ with ammonium acetate $(2 \mathrm{mM})$ were prepared. A pump attached to the ESI/MS system (Model 980532, Harvard) injected these solutions containing $\mathrm{ZnPT}$ and an amino acid. The flow rate was $10 \mu \mathrm{l} / \mathrm{min}$. The peak intensities were obtained from the average of the measurements $(n=4)$.

The conditions of the ESI/MS/MS analysis were as follows: argon gas pressure, 2.2 mTorr; CID energy, $-45 \mathrm{eV}$; precursor ions, $\mathrm{m} / \mathrm{z} 345$ and 156.

\section{Results and Discussion}

\section{Ligand exchange of ZnPT by mixing with an amino acid}

For the mass spectral investigation of ZnPT by ESI/MS, the $\mathrm{m} / \mathrm{z} 317$ ions, which were assigned as the protonated $\mathrm{ZnPT}$, were observed. In the case of amino acids, the ion peaks assigned as the corresponding protonated ion were observed.

The ESI/MS spectrum of ZnPT in the presence of an amino acid showed several peaks corresponding to the ZnPT ligand-exchange complexes, such as [ZnPT- L+Amino acid] ${ }^{+}$, [ZnPT$2 \mathrm{~L}+2$ Amino acid-H $]^{+}$, [2ZnPT- $2 \mathrm{~L}+$ Amino acid-H $]^{+}$(L; the pyrithione ligand of ZnPT). The [ZnPT$\mathrm{L}+$ Amino acid] $]^{+}$ion was observed for every amino acid. The ESI mass spectrum of ZnPT in the presence of His is shown in Figure 2.

The relative peak intensities of the ion peaks assigned to [ZnPT- L+Amino acid] ${ }^{+}$, [ZnPT- 2L+2 Amino acid-H] ${ }^{+}$and [2ZnPT- $2 \mathrm{~L}+$ Amino acid-H $]^{+}$are summarized in Table 1. The peak intensities of [ZnPT- L+Amino acid] ${ }^{+}$were higher than those of the other ligand exchange complexes.

For most amino acids, the intensities of the observed ion peaks of the ligand exchange complexes other than [ZnPT- L+Amino acid] ${ }^{+}$were below $10 \%$ compared to the peak intensity of $[\mathrm{ZnPT}+\mathrm{H}]^{+}$, and the peak intensities of the ligand-exchange complex, [ZnPT- $2 \mathrm{~L}+2$ Amino acid-H] $]^{+}$, and [2ZnPT- $2 \mathrm{~L}+$ Amino acid-H] ${ }^{+}$, were below $10 \%$ compard to the peak intensity of [ZnPT- L+Amino acid] ${ }^{+}$. However, in the case of Arg, the peak intensity of the ion peak assigned to [ZnPT-2L+2 Amino acid-H $]^{+}$was about $80 \%$ of that of [ZnPT- L+Amino acid] ${ }^{+}$. This result would be due to the formation of the stable zinc complex with two amine groups at the arginine side chain.

In addition, the transition of the peak patterns of the ligand-exchange complexes of ZnPT by changing the drift voltage from 30 to $70 \mathrm{~V}$ was observed. As a result, the significant transition of the peak intensities of the ligand exchange complexes of ZnPT with an amino acid was not observed.

\section{Comparison of reactivity of amino acid to $\mathrm{ZnPT}$}

In order to compare the reactivity of the amino acids with $\mathrm{ZnPT}$, the change in the peak intensity of the protonated ion of the amino acids $(30 \mu \mathrm{M})$ was observed by adding the solution containing ZnPT at the different concentrations (the final concentration of $\mathrm{ZnPT}$ were at 0, 10, 20, 30, 40 and $50 \mu \mathrm{M}$.). The ratios of peak intensities of observed complexes of amino acids with ZnPT, [ZnPT- L+Amino

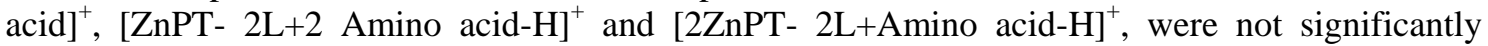
changed by the concentration of ZnPT. The ratio of the peak intensity $\mathrm{I} / \mathrm{I}_{0}$, $\mathrm{I}$ is the peak intensity of of $[\text { Amino acid }+\mathrm{H}]^{+}$at the $\mathrm{ZnPT}$ concentration $50 \mu \mathrm{M}$ and $\mathrm{I}_{0}$ is the initial peak intensity of the amino acid, and pKa of amino acids were summarized in Table 2.

It is thought that the order of the reactivity of the amino acids to ZnPT would be in accordance with the order of the value of $\mathrm{I} / \mathrm{I}_{0}$. The values of the $\mathrm{I} / \mathrm{I}_{0}$ for His and Cys were lower than that of other amino acids. This fact indicates that His and Cys show the high reactivity to ZnPT.

It is well known that both zinc/Cys and zinc/His interactions play an important role at in vivo reactions. The thiol group of $\mathbf{C y s}$ and the $\mathrm{N}$ atom of His coordinate with zinc in protein, such as zinc finger motif. ${ }^{17,18,19}$ These facts are accordant with the result that $\mathbf{C y s}$ and His reveals high reactivities to ZnPT. There was no correlation between the order of reactivities to $\mathrm{ZnPT}$ and pKa of the amino acids. This result indicates that the attack by carboxyl group of amino acids to ZnPT is not a main factor for the ligand-exchange reaction of ZnPT with amino acids.

Based on this evaluation, His shows the highest reactivity of the amino acids. In order to study the binding site of His with ZnPT, the solution with the mixed ZnPT and His was measured by ESI tandem mass spectrometry. The product ion mass spectra of [ZnPT- L+His $]^{+}(\mathrm{m} / \mathrm{z} 345)$ are shown in Figures 3. The iminium ion of His was observed as the main product ions for both precursor ions. 
When the carboxyl group of His is related to the coordination of His to ZnPT, it is difficult to fragment the carboxyl group of His at the MS/MS interface. Therefore, this result indicates that the other functional group of His would be related to the coordination of His with ZnPT.

\section{Ligand exchange of ZnPT with $\mathbf{N}_{\alpha}$-(tert-butoxycarbonyl)-L-histidine (BocHis)}

The solution of ZnPT mixed with $\mathrm{N}_{\alpha}$-(tert-butoxycarbonyl)-L-histidine (BocHis), in which the amino group of His was substituted by the steric component, was measured by ESI/MS. The obtained spectrum is shown in Figure 4. The ion peaks assigned as the ligand exchange complexes, such as [ZnPT- L+BocHis-isobutylene $]^{+}$and $[\mathrm{ZnPT}-\mathrm{L}+\mathbf{B o c H i s}]^{+}$, were detected. The value of $\mathrm{I} / \mathrm{I}_{0}$ for BocHis in Table 2 was lower than that of His. This result indicates that the histidine nitrogen atoms and the amino group of His would contribute to the coordination of His to ZnPT. It has been reported that the zinc ions are bound to the several peptitases by their histidine nitrogen atoms. ${ }^{20}$ Based on these facts, the [ZnPT- L+His] ${ }^{+}$complex would be a stable structure as shown in Figure 5, and that would result in the high reactivity of His to ZnPT.

\section{Ligand exchange of ZnPT with a peptide (Leucine-Enkephalin)}

The complexation of ZnPT with a peptide was studied. Leucine-Enkephalin was selected as substrates for the reaction with ZnPT. The compound is often used as a model peptide for the research in mass spectrometry. ${ }^{21}$ The ESI mass spectrum of the ZnPT $(50 \mu \mathrm{M})$ - peptide (Leucine-Enkephalin: $10 \mu \mathrm{M}$ ) mixed solution is shown in Figures 6. Leucine-Enkephalin formed the complex with ZnPT assigned as the [ZnPT- L+Leucine-Enkephalin] ion $(\mathrm{m} / \mathrm{z} 745)$. The binding sites of the peptide with ZnPT are not clear. The most reactive amino acid in the peptide based on the results in Table 2 was Tyr, and the amino acid would be the center of the reaction between the peptide and ZnPT. As a result, it was clarified that the ligand exchange of ZnPT could occur by mixing ZnPT with peptides.

\section{Conclusions}

We observed and evaluated the reactivity of ZnPT with amino acids. As a result, ZnPT forms the [ZnPT- L+amino acid] ${ }^{+}$complexes through the ligand exchange with amino acids. A similar reaction occurred between ZnPT and a peptide. These results indicated that such a reactivity of ZnPT with amino acids would cause the toxicities of ZnPT, such as the teratogenic effect on aquatic organisms. Furthermore, the reactivity of ZnPT was different for the different amino acids, and His and Cys, in particular, showed a high reactivity to form the [ZnPT- L+amino acid $]^{+}$.

The procedure described in this study is very simple and suggested only a simple model for the reaction of amino acids with the pollutant. However, it provides significant information for estimating the reaction of the pollutant with biological materials within the living body. The procedure would be useful for the toxicological study of other environmental pollutants, which interact with proteins.

\section{Acknowledgements}

This work was partially supported by a Grant-in-Aid for Scientific Research (B) and by the Research and Development Organization of Industry-University Corporation from the Ministry of Education, Culture, Sports, science and Technology of Japan.

\section{References}

[1] Goka K. Environ. Res., 81 (1999) 81-83.

[2] Kobayashi N, Okamura H. Marine Pollut. Bull., 44 (2002) 748-751.

[3] Sánchez-Bayo F, Goka K. Aquatic Toxicol., 74 (2005) 285-293.

[4] Okamura H, Watanabe T, Aoyama I, Hasobe M. Chemosphere, 46 (2002) 945-951.

[5] Eriksson Winklund AK, Börjesson T, Wiklund SJ. Marine Pollut. Bull., 52 (2005) 96-99

[6] Harino H, Yamamoto Y, Eguchi S, Kawai S, Kurokawa Y, Arai T, Ohji M, Okamura H, Miyazaki N. Arch. Environ. Contam. Toxicol., 52 (2007) 179-188.

[7] Lagunowich LA, Stein AP, Reuhl KR. Neurotoxicology, 15 (1994) 123-132.

[8] Skoulis NP, Barbee SJ, Jacobson-Kram D, Putman DL, San RH. J. Appl. Toxicol. 13(4) (1993) 283-289.

[9] Moriwaki H, Nakano T, Tsunoi S, Tanaka M. Rapid Commun. Mass Spectrom., 15 (2001), 
2208-2210.

[10] Concina B, Hvelplund P, Nielsen AB, Nielsen SB, Rangama J, Liu B, Tomita S. J. Am. Soc. Mass Spectrom., 17 (2006) 275-279.

[11] Pocsfalvi G, Ritieni A, Randazzo G, Dobó A, Malorni A. J. Agri. Food Chem., 48 (2000) 5795-5801.

[12] Benkestock K, Edlund PU, Roeraade J. Rapid Commun. Mass Spectrom., 19 (12) (2005) 1637-1643.

[13] Ngu TT, Sturzenbaum SR, Stillman MJ. Biochem. Biophys. Res. Commun., 351 (1) (2006) 229-233.

[14] Mineo P, Vitalini, D, La Mendola D, Rizzarelli E, Scamporrino E, Vecchio G. Rapid Commun. Mass Spectrom., 16 (2002) 722-729.

[15] Xu Y, Zhang X, Yergey AL. J. Am. Soc. Mass Spectrom., 7 (1996) 25-29.

[16] Lu H, Guo Y, Yang P. J. Am. Soc. Mass Spectrom., 15 (2004) 1612-1615.

[17] Diakun GP, Fairall L, Klug A. Nature, 324 (1986) 698-699.

[18] Marshall HE, Merchant K, Stamler JS. FASEB J., 14 (2000) 1889-1900.

[19] Hunt JA, Ahmed M, Fierke CA. Biochemistry, 38 (1999) 9045-9062,

[20] Lipscomb WN, Strater N. Chem. Rev., 96 (1996) 2375-2433.

[21] Emory JF, McLuckey SA. J. Am. Soc. Mass Spectrom., 20 (2009) 180-187.

Figure captions

Fig.1 Chemical structure of zinc pyrithione (ZnPT) and pyrtihione ligand.

Fig.2 ESI mass spectrum of ZnPT $(100 \mu \mathrm{M})$ - His $(30 \mu \mathrm{M})$ aqueous solution.

Fig.3 Product ion mass spectra of [ZnPT-L+His] ${ }^{+}(\mathrm{m} / \mathrm{z} 345)$.

Fig.4 ESI mass spectrum of ZnPT $(100 \mu \mathrm{M})$-BocHis $(30 \mu \mathrm{M})$ aqueous solution.

Fig.5 Schematic representation of the formation of ZnPT-L+His complex.

Fig.6 ESI mass spectrum of ZnPT $(50 \mu \mathrm{M})$ solution mixed with Leucine-Enkephalin (Tyr-Gly-Gly-Phe-Leu) $(10 \mu \mathrm{M})$. 
Table 1 Relative peak intensity data of ESI/MS analysis for complexation of ZnPT (50 $\mu \mathrm{M})$ with amino acids $(30 \mu \mathrm{M})$

\begin{tabular}{|c|c|c|c|c|c|}
\hline \multirow[b]{2}{*}{ Entry } & & \multicolumn{4}{|c|}{ Relative peak intensity $[\%]^{a, b}$} \\
\hline & & {$[\mathrm{ZnPT}+\mathrm{H}]^{+}$} & {$[\mathrm{ZnPT}-\mathrm{L}+\mathrm{A}]^{+}$} & {$[\mathrm{ZnPT}-2 \mathrm{~L}+2 \mathrm{~A}-\mathrm{H}]^{+}$} & {$[2 \mathrm{ZnPT}-2 \mathrm{~L}+\mathrm{A}-\mathrm{H}]^{+}$} \\
\hline 1 & Lys & 100 & 25 & 0 & 0 \\
\hline 2 & Gly & 100 & 15 & 0 & 0 \\
\hline 3 & Ala & 100 & 27 & 0 & 0 \\
\hline 4 & Arg & 100 & 11 & 8.2 & 0 \\
\hline 5 & His & 100 & 63 & 0 & 5.4 \\
\hline 6 & Asp & 100 & 30 & 0 & 0 \\
\hline 7 & Glu & 100 & 25 & 0 & 3.2 \\
\hline 8 & Asn & 100 & 36 & 0 & 0 \\
\hline 9 & Gln & 100 & 36 & 0 & 3.8 \\
\hline 10 & Ser & 100 & 23 & 0 & 0 \\
\hline 11 & Thr & 100 & 32 & 0 & 3.2 \\
\hline 12 & Tyr & 100 & 50 & 0 & 5.8 \\
\hline 13 & Cys & 100 & 0 & 0 & 0 \\
\hline 14 & Met & 100 & 50 & 5.0 & 0 \\
\hline 15 & Phe & 95 & 100 & 0 & 8.5 \\
\hline 16 & Trp & 93 & 100 & 4.6 & 11 \\
\hline 17 & Val & 100 & 56 & 0 & 7.5 \\
\hline 18 & Leu & 89 & 100 & 0 & 4.2 \\
\hline 19 & Ile & 73 & 100 & 0 & 4.2 \\
\hline 20 & Pro & 100 & 76 & 0 & 6.6 \\
\hline
\end{tabular}

${ }^{a}$ The relative peak intensities were calculated by the average values of peak intensities $(n=4)$.

${ }^{\mathrm{b}} \mathrm{A}$ : amino acid. L: pyrithione ligand. 
Table 2 The change of the peak intensity for amino acids by adding ZnPT ( $50 \mu \mathrm{M}$ ).

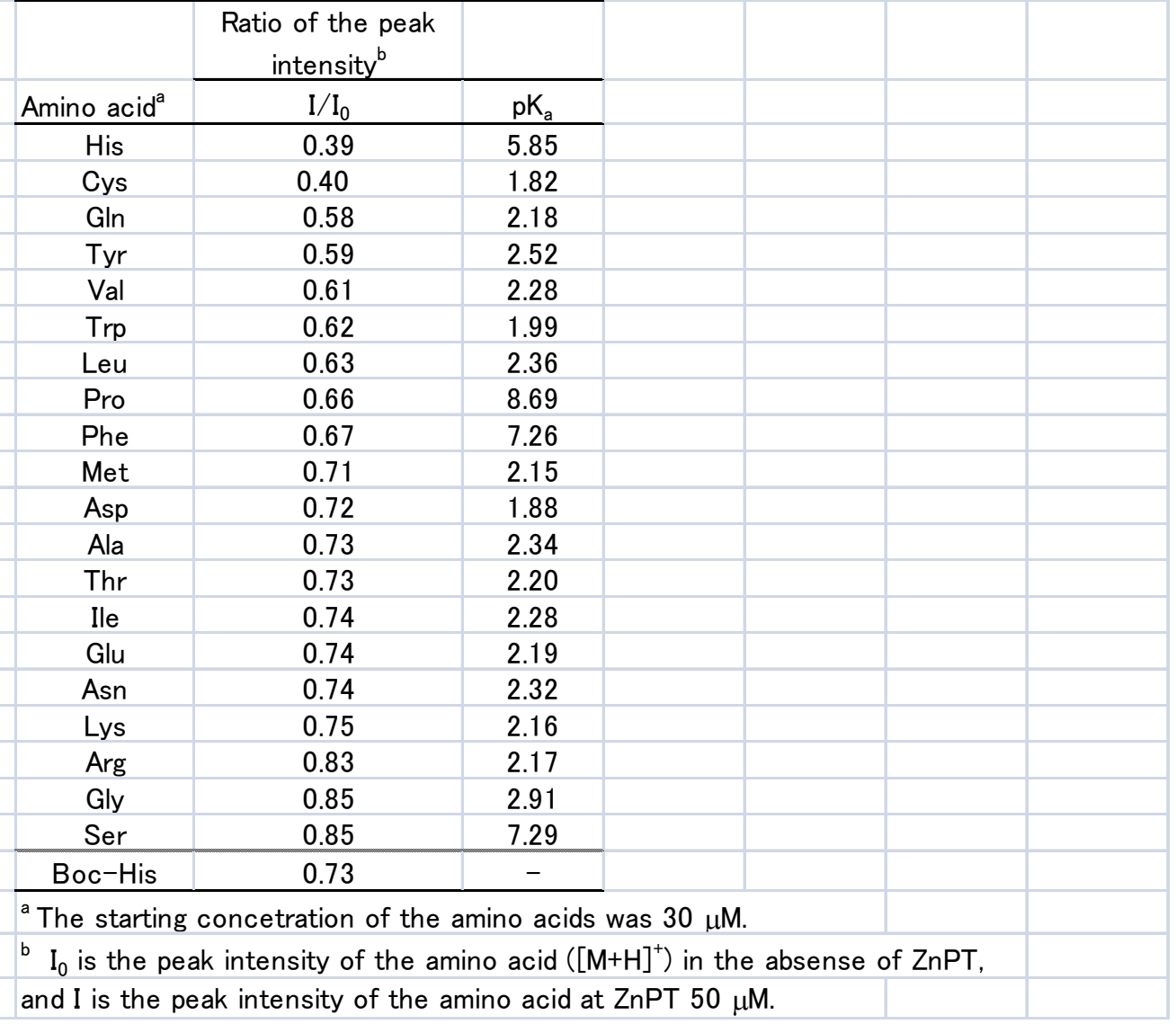

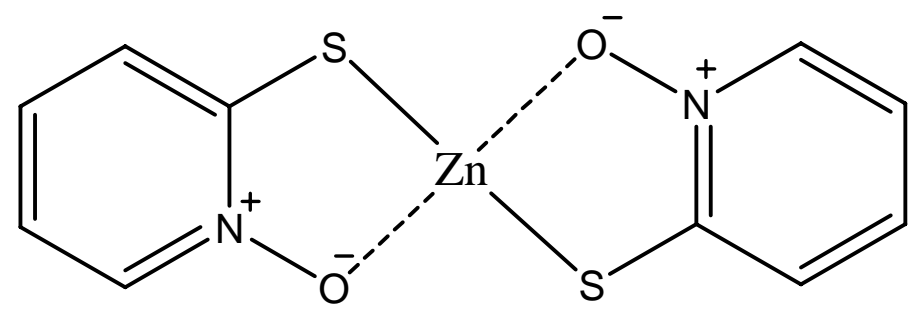

ZnPT<smiles>[O-][n+]1ccccc1[S-]</smiles>

L: Pyrithione ligand 


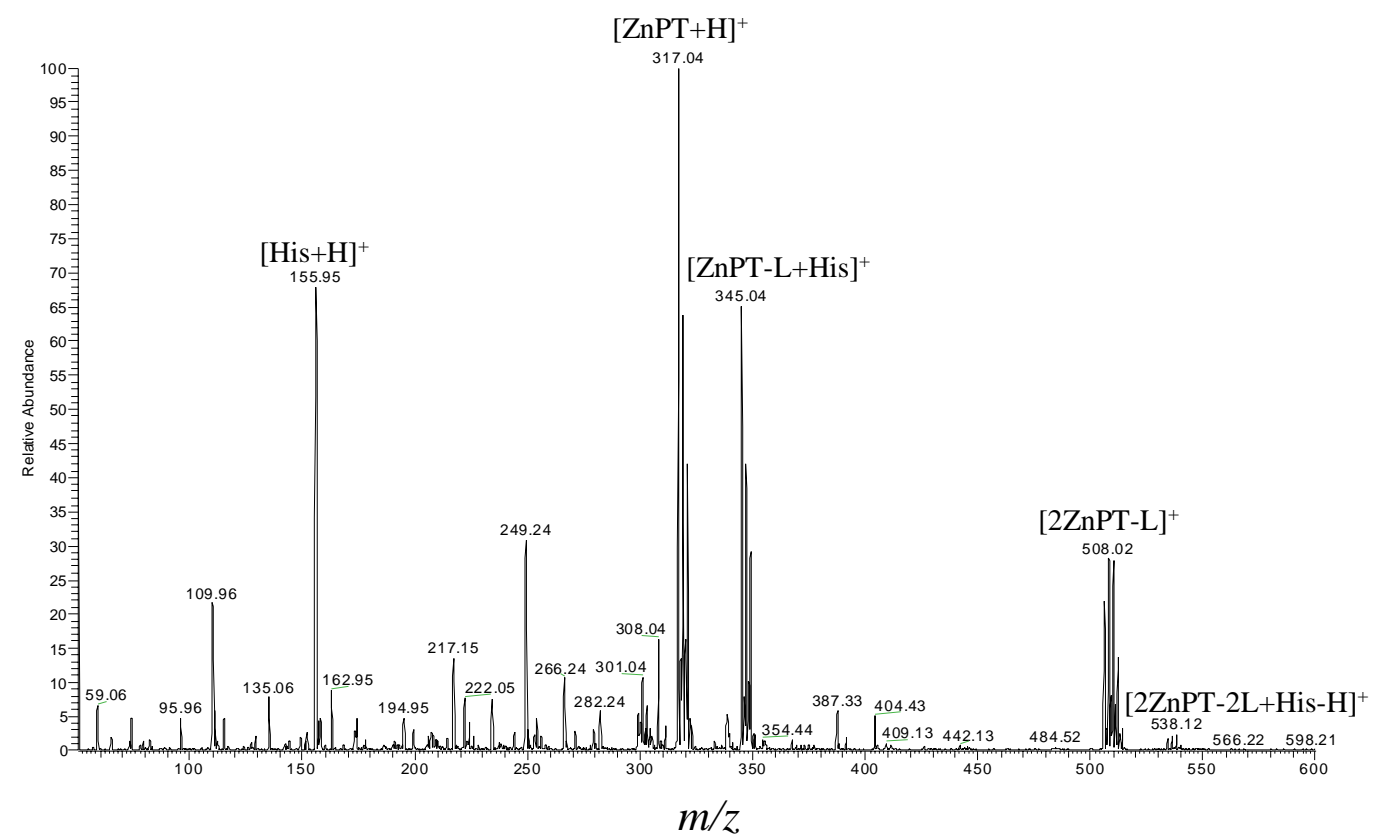

Figure 2

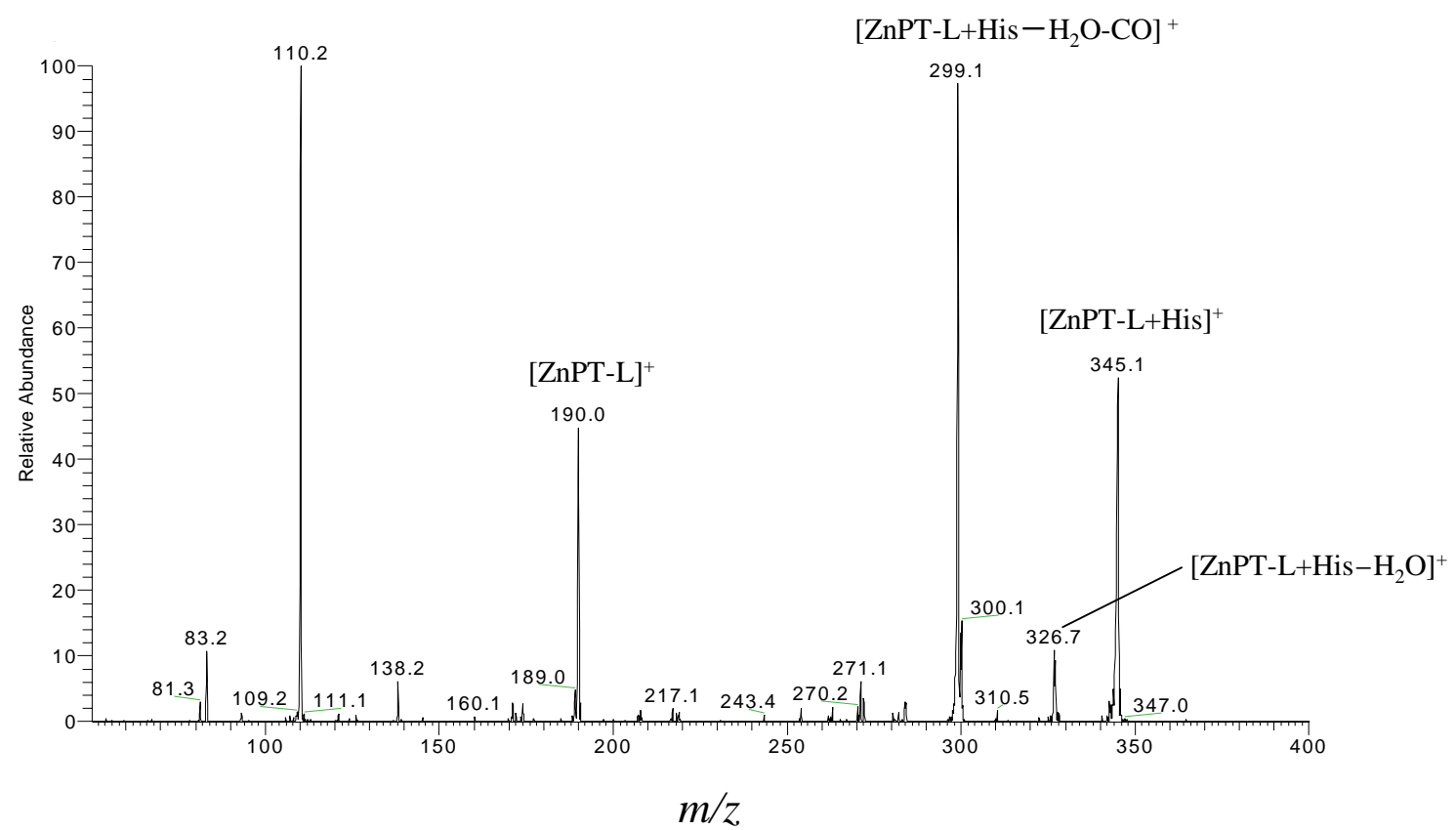

Figure 3 


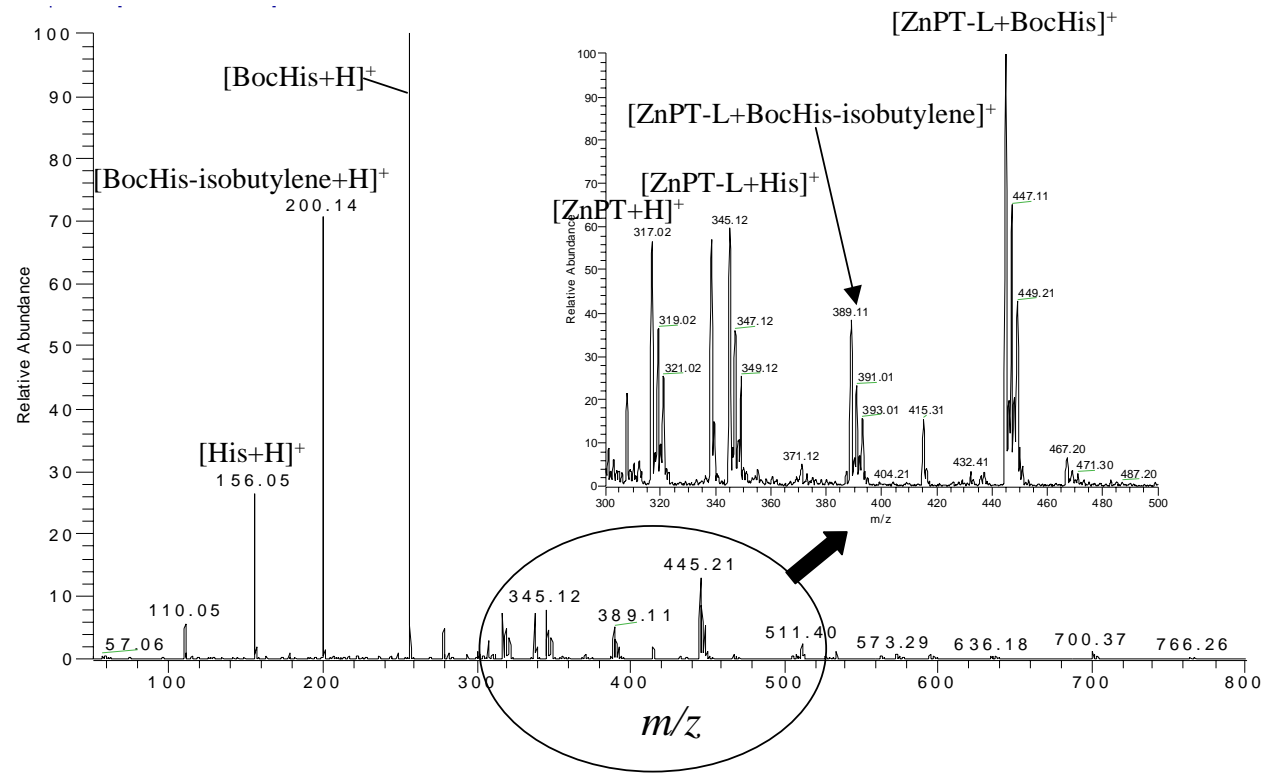

Figure 4

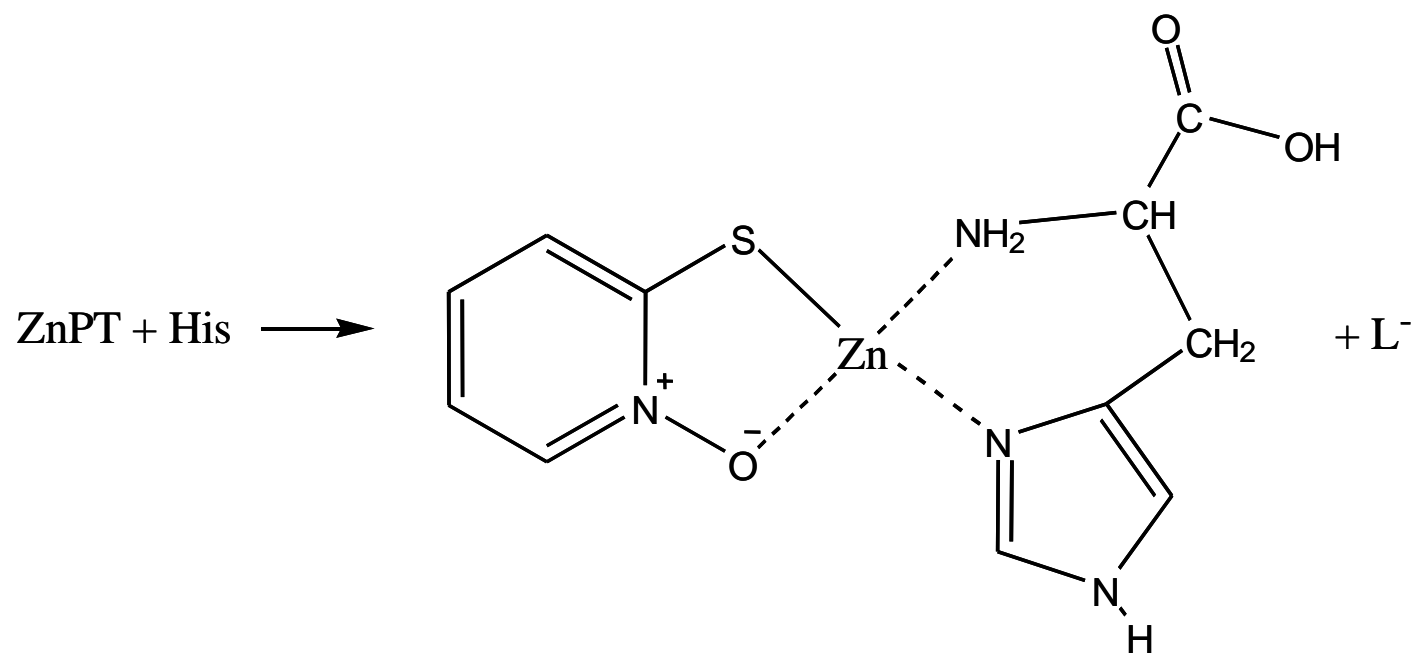

Figure 5 


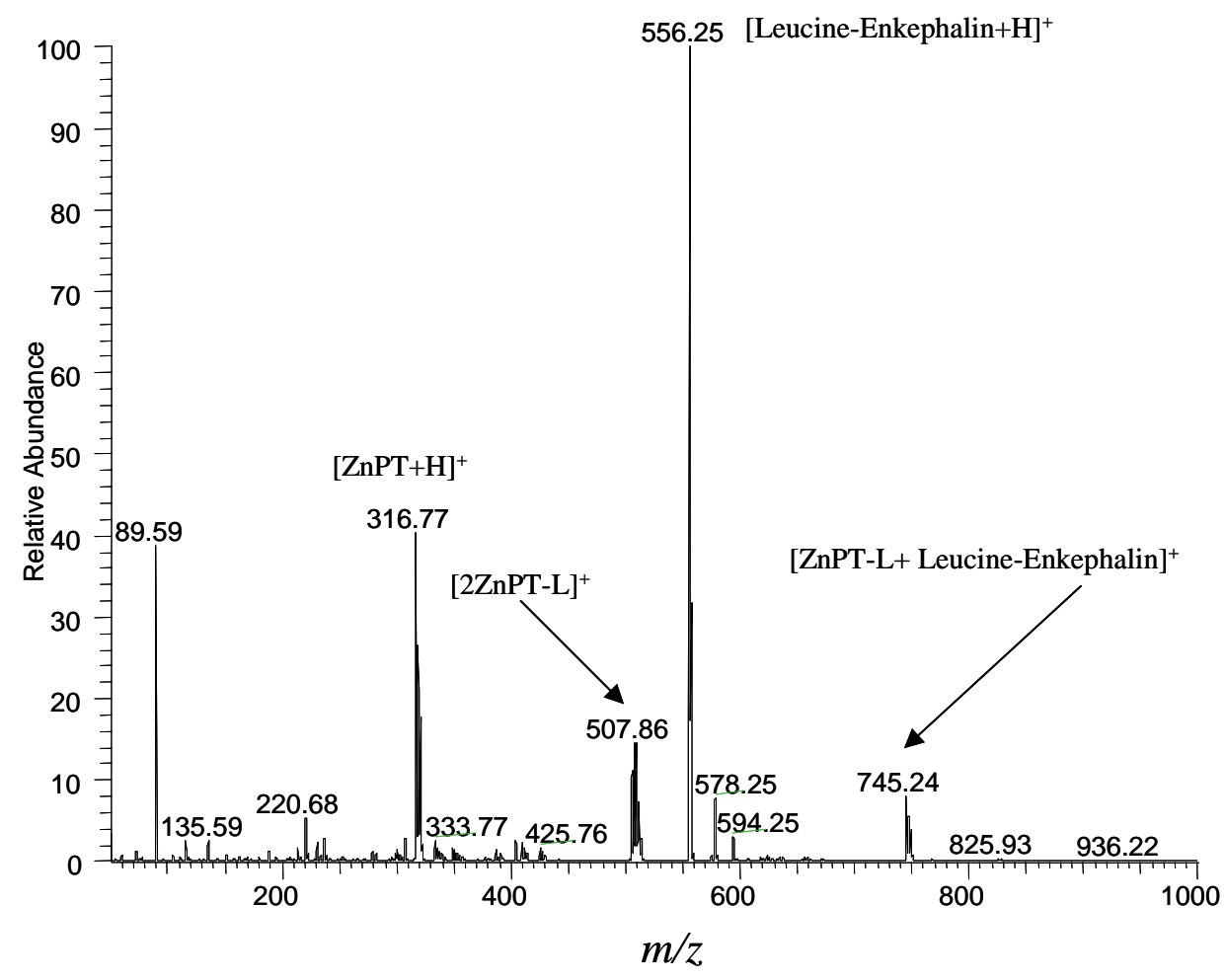

Figure 6 